\title{
O TEMPO NO CONTO "TESTEMUNHA", DE LÍDIA JORGE
}

\author{
Letícia Braz da Silva* \\ Universidade Federal de Goiás
}

Resumo: O presente artigo tem por fito analisar a estrutura temporal do conto "Testemunha", de Lídia Jorge, a partir da aplicação teórica da metodologia do estudo do texto narrativo proposto por Gérard Genette, mas se apropriando também de outros teóricos que estudaram o assunto: Paul Ricoeur e Benedito Nunes. O conto em questão permite esse tipo de abordagem, pelo fato da escritora se valer do tempo narrativo como categoria central em sua história, apresentando evocações de cenas da infância, no período escolar, rememoradas pela protagonista. A alteração da ordem temporal (anacronia) é, portanto, evidente nesta narrativa, tendo a organização discursiva subvertida por meio de recuos temporais (analepses), que contribuem para a motivação da história. Como método, o levantamento de referências temporais contribuiu tanto no entendimento da configuração da analepse no discurso narrativo de "Testemunha", quanto em sua classificação no que concerne à tipologia narrativa: narração ulterior, em sua totalidade. Por se tratar de um conto contemporâneo, notam-se inversões da ordem dos acontecimentos, por vezes, sem dizer; sendo cabível, portanto, a análise do aspecto linguístico (expressões, indícios temporais) para auxiliar nas identificações das variações temporais e, consequentemente, do movimento retrospectivo do conto de Lídia Jorge.

Palavras-chave: Tempo Narrativo. Anacronia. Analepses. Lídia Jorge. "Testemunha”.

\section{Introdução}

Para estudar um texto narrativo, a crítica opta, quase sempre, por um dos elementos narrativos (enredo, personagens, tempo, espaço, narrador, visão) como foco de análise. Ao adotar o tempo como aspecto de investigação, o analista do texto narrativo se depara com a dualidade temporal: o tempo da história e o tempo da narrativa. Segundo Gérard Genette, essa dualidade entre o tempo do que é contado com o tempo da narrativa possibilita distorções e mudanças temporais.

A relação de ambos permite entender a disposição dos fatos, sua discordância, ou

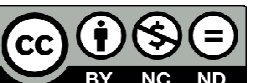

BY NC ND Esta obra está licenciada sob uma Licença Creative Commons.

\footnotetext{
* Mestra em Letras e Linguística, área Estudos Literários, pelo Programa de Pós-Graduação em Letras e Linguística da Universidade Federal de Goiás, fazendo parte da linha de pesquisa "Literatura, História e Imaginário". Possui graduação em Letras nas modalidades Licenciatura em Língua Portuguesa e Bacharelado em Estudos Literários pela mesma instituição.
} 
não, em relação à ordem dos acontecimentos, e sua representação na história. Caso haja uma alteração, a não linearidade do tempo é apresentada por meio de analepses (retrospecção) ou de prolepses (antecipação), que auxiliam na caracterização de personagens, na reintegração de acontecimentos, além de criar expectativas ao leitor (GENETTE, s/d; REIS; LOPES, 2007).

Essa alteração da ordem dos eventos, denominada anacronia, não é uma criação da literatura moderna, é um recurso tradicional da narrativa literária, sendo encontrada já nos poemas homéricos no começo in medias res, em que o relato se inicia em um momento adiantado da ação principal, com os fatos anteriores sendo recuperados posteriormente por meio de analepses (NUNES, 2008; REIS; LOPES, 2007).

Por essas inversões temporais serem comuns, muitos escritores utilizam o tempo como categoria narrativa central de seus textos, assim como a escritora portuguesa Lídia Jorge faz em seu conto “Testemunha”, publicado em 1983, na Revista Colóquio / Letras, de Lisboa, incluído posteriormente em Marido e outros contos (1997). A escritora se vale de técnicas de retrospecção para relatar a história de uma personagem que evoca cenas que a perturbam e justificam seu sofrimento.

Dessa forma, é necessário explicitar as mudanças, as evoluções recorrentes neste relato, por estas propiciarem ao leitor o entendimento da sucessão do tempo ou da cronologia discorrida no conto, ressaltando, porém, que pensar a cadeia de acontecimentos somente como um caráter lógico é um fator prejudicial. É errôneo considerar que as conexões estão sempre inter-relacionadas, isso nos limita a conexões somente cronológicas e, por assim dizer, a uma prioridade qualitativa (BAL, 2009). A narrativa segue um procedimento de organização lógico-temporal, que pode apresentar alguns efeitos de ordem e de ritmo, como a analepse, o encaixe e o seguimento. Efeitos esses que podem ser percebidos em “Testemunha”.

A estrutura temporal do conto de Lídia Jorge será tratada com consideração, com a própria narrativa informando ao leitor situações sobre os acontecimentos e fornecendo indícios interpretáveis da variação temporal, que serão o objeto de análise: tempos verbais que denotam eventos anteriores em relação à ação narrativa (GENETTE, s/d; RICOEUR, 1995).

Sendo assim, a intenção do presente artigo é problematizar a categoria do tempo narrativo no conto “Testemunha”, de Lídia Jorge, a partir da metodologia proposta por Gérard Genette, em o Discurso da narrativa (s/d), subsidiada por Paul Ricoeur e Benedito Nunes. O tempo é o foco da análise por ser o elemento que modifica a sequência narrativa, além disso, as implicações linguísticas (marcas temporais e tempos verbais) evidenciam sua relevância 
em relação às outras categorias, mas não deixando de correlacioná-las, e na identificação do movimento retrospectivo.

\section{A ordem temporal como estratégia enunciativa}

Como característico na obra de Lídia Jorge, "Testemunha” se estrutura de forma complexa. Tal narrativa requer uma leitura minuciosa, visto que as construções sintáticas, em sua maioria, foram construídas de maneira que assinala ambiguidade: sendo difícil distinguir, imediatamente, o que é expresso por meio da fala ou do pensamento, e quem enuncia e a quem se referem (GENETTE, s/d).

Em suma, a história relata o encontro entre duas pessoas: Zuzete e uma visita inominada (interlocutor) ${ }^{1}$. A conversa se passa na casa de Zuzete, provavelmente, nos Estados Unidos, onde ambas contam sobre suas vidas, desde o tempo que ficaram distantes, e relembram situações de quando moravam no "Vale da Vaca, a tantos do tantos de mil novecentos e cinquenta e tantos" (JORGE, 1983, p. 37). Estruturalmente, o conto se dispõe de um relato primeiro, que trata do próprio encontro, e da evocação de eventos anteriores "ao momento em que se encontra o relato" ${ }^{2}$ (RUDIN, 2003, p. 8; tradução nossa).

O primeiro relato, ou narrativa primeira, é o nível temporal da narrativa que permite a anacronia se definir como tal, por enquadrar, neste caso, as analepses na história (RUDIN, 2003). Dessa forma, em relação à narrativa que insere a analepse, a anacronia caracteriza "uma narrativa temporalmente segunda" (GENETTE, s/d, p. 47), porém, não subordinada totalmente à primeira.

A própria narrativa infere indícios, ora diretos, ora indiretos, a respeito da ordem temporal. A referência do tempo é alterada propositalmente pelo narrador e a reorganização da ordem não seria pertinente, pois eliminaria o efeito de inquietude de Zuzete transposta na estrutura estética do conto. A alteração da ordem cronológica dos acontecimentos incide na representação dramática do texto narrativo, com a cena do encontro sendo um episódio posterior na ordem das sequências (GENETTE, s/d; NUNES, 2008). Por isso, "Testemunha" evidencia uma anacronia.

A análise temporal de "Testemunha" conta, resumidamente, com sete segmentos repartidos por duas posições temporais: o agora (o encontro, o momento da visita) e o antes

\footnotetext{
${ }^{1}$ Ao contrário do que foi afirmado por Maria Madalena Gonçalves, em seu texto Lídia Jorge: a arte de narrar Marido e outros contos (2000), não se pode afirmar que a visita se trata de uma amiga, pois o conto não apresenta indícios que especifiquem o gênero do interlocutor, podendo ser qualquer pessoa testemunha do fato, até mesmo, um dos garotos que atacaram Zuzete.

2 “[...] en el momento en que se desarrolla" (RUDIN, 2003, p. 8).
} 
(lembranças da personagem) (GENETTE, s/d). Tais elementos denominados aqui de A, B, C, $\mathrm{D}, \mathrm{D}_{1}, \mathrm{D}_{2}, \mathrm{D}_{3}$ ocupam, respectivamente, na história, as posições cronológicas 7, 6, 5, 1, 2, 3, 4. Neste discurso narrativo, é possível perceber a alternância das evocações passadas - ora apresentadas durante o diálogo, ora fazendo parte somente da memória da personagem - com o tempo da situação inicial (relato básico).

O segmento (A) trata da cena inicial da narrativa, que comporta as analepses, isto é, do próprio encontro na casa de Zuzete. Os recuos temporais apresentados consistem no namoro e no noivado com Sandro (B); na situação de suas tias no lameiro (C) e no tempo de escola (D), subdividido em: a descrição da sala de aula $\left(D_{1}\right)$, a cena da retrete $\left(D_{2}\right)$ e o ato do estupro $\left(D_{3}\right)$.

A suspeita de retrospecção na história aparece logo de início. O narrador descreve como Zuzete se porta antes da chegada da visita inesperada, mostrando uma personagem inquieta e dispersa em suas próprias lembranças: "Zuzete de lado, Zuzete de frente, Zuzete de olhar só líquido, muito distante, perdido no longe longe duma apagada memória" (JORGE, 1983, p. 35; grifo nosso). A expressão "longe longe" enfatiza ainda mais a distância percorrida pela memória da protagonista, além de evidenciar a intensidade de suas lembranças.

Zuzete, após ouvir sobre como está o local onde vivia, conta que tem dois filhos Donald e Margaret - e pega um álbum de fotografias para rememorar, de maneira, possivelmente, cronológica, momentos de sua vida. O manusear do álbum mostra um tempo passado (B), mas que não é desenvolvido na história e, sim, citado de maneira acelerada, na intenção de mostrar à visita seu marido:

Então Zuzete fez saber de tudo e do urgente, que Sandro não estava, tinha ido fazer compras com as crianças, vais vê-los. São dois. Disse Zuzete com os dedos abertos a indicar as criaturas, e puxou de um álbum logo ali à mão, por onde folheando com o dedo, se podia acompanhar o namoro feito aos domingos, a festa de noivado num bar, com velas e parabéns em papel. Este é o meu marido (JORGE, 1983, p. 35-36).

Adiante, ao ser questionado por Zuzete sobre o lameiro e suas tias, o interlocutor relata que estas continuam fazendo o mesmo de sempre (C), vão até o lameiro e "levam a roupa à cabeça, torcem-na nas pedras, secam-na nas árvores" (JORGE, 1983, p. 36). Esta lembrança é frequente no decorrer da história, com a personagem dizendo que seria mais feliz se não fosse a condição de suas tias, sendo entendida somente no final o porquê dessa repetição e do assombro ao se lembrar delas.

A repetição é dada de maneira gradual, em cinco momentos. A menção feita às tias é apresentada, de maneira intercalada, em cada recuo temporal exposto durante a conversa e nas 
lembranças de Zuzete: (3) "São dois os nossos filhos e chamam-se Donald e Margaret, se não fosse a lembrança das minhas tias, éramos felizes" (JORGE, 1983, p. 37), (4) "Só me ensombra neste momento a lembrança das minhas tias" (JORGE, 1983, p. 38), (5) "Sandro, estou aqui e estou a pensar nas minhas tias de roupa às costas, transidinhas de frio, lameiro adiante. Não posso ser feliz" (JORGE, 1983, p. 39).

(1) Ainda lhe custava a crer, e tinha de perguntar directamente pelo lameiro, se ainda lá iam lavar as suas tias. [...] (2) Mas estou aqui e estou a pensar nas minhas tias, tão sós, no lameiro, a bater as anáguas. Devem estar muito curvadinhas (JORGE, 1983, p. 36).

A alternância entre a evocação das tias com as outras retrospecções evita a monotonia do conto e aumenta a expectativa durante a leitura. Afinal, o leitor quer saber o motivo de tanta aflição da protagonista, ao se lembrar daquelas que ficaram no Vale da Vaca. Aos poucos, cada recuo ao passado suplementa o porquê de todo o sofrimento, por meio da inversão do que seria a relação causa e consequência (TODOROV, 1972), sendo esta última apresentada inicialmente no relato primeiro com a descrição do tormento e mudança de humor de Zuzete.

A lembrança do tempo de escola (D) complementa tal compreensão. Este recuo temporal, especialmente, é imprescindível para o leitor saber a relação da presença do interlocutor com o aumento da angústia de Zuzete e, concomitantemente, compreender o próprio título. Sem esta analepse haveria uma lacuna na história. A conversa entre ambos sobre como era a sala de aula $\left(\mathrm{D}_{1}\right)$ fez com que a personagem rememorasse a descoberta dela sentada sozinha no banheiro lanchando e a perversão que foi acometida no trigal. Porém, as situações da retrete $\left(D_{2}\right)$ e do estupro $\left(D_{3}\right)$ não são exteriorizadas à visita, sendo somente pensamentos de Zuzete contados pelo narrador; o que mostra a onisciência deste que, mesmo fora do nível da história, sabe mais que todos, relatando fatos e sentimentos mais íntimos da personagem (GENETTE, s/d).

A cena do estupro $\left(D_{3}\right)$ seria contada logo depois que Zuzete mencionou a situação de suas tias pela primeira vez; porém a cena, que se inicia com a descrição dos trigais, foi interrompida, passando para o momento em que a protagonista mostrava sua casa ao interlocutor. A retomada da cena se dá mais à frente assim que Zuzete é questionada, pela visita, sobre como conheceu Sandro.

Zuzete mostrava ter pressa e sentava-se na retrete como se andasse com o horário das funções invertido, e só de lá saía quando já se faziam rodas e se produzia canto. O que fará lá dentro Zuzete? Isso, até que um dia alguém se pôs às cavalitas de alguém e descobriu que Zuzete tasquinhava o seu pão sentada na tábua desse pivete. 
O alarido da descoberta foi tão grande que Zuzete saiu de lá trocando as pernas sem saber para onde olhar $[\ldots]$.

$[\ldots]$

Os meninos tinham largado os bibes em qualquer poiso e estavam de mãos a abanar como se a ameaça fosse verdade. Então uma das meninas disse, apontando Zuzete. Aquela, aquela que não tem calças. Laurentino deu um estalo com a língua como os ladrões de alpergata a chamar a chusma. E todos à uma. Distribuíram-se pelos pulsos e pelos braços, pelos artelhos, baloiçaram Zuzete como se fosse saca, atiraram-na dentro do trigo, e porque afinal Zuzete usava roupa interior amordaçada de elástico, a luta foi demorada e entrecortada de grandes brados, até que Laurentino atirou a cueca ao ar por cima da cabeça de todos. Zuzete de coxa aberta no meio do trigo, Zuzete sem bolsa, Zuzete sem laço, Zuzete de choro alto, magoado, palhetas de aço a meterem-se pelos ouvidos dos colmos (JORGE, 1983, p. 37-38).

Como se pôde notar, até então, as relações que unem os segmentos entre si ora se complementam, ora são independentes (GENETTE, s/d). Os fragmentos de espaço e tempo colidem, saltam de uma sequência para outra de maneira inesperada, sem uma transição lógica. Essa estrutura utilizada por Lídia Jorge apresenta e intensifica o emocional da personagem, representado pelos intervalos existentes entre os episódios aqui explicitados (GONÇALVES, 2000).

Sendo assim, o narrador dá forma ao mundo narrado ao nível do texto, primordialmente, por meio da disposição da ordem temporal, na qual os acontecimentos são apresentados na narrativa, e também pela escolha da perspectiva (ponto de vista, focalização, visões). ${ }^{3}$

Zuzete é a personagem focalizadora da narrativa e suas recordações acarretam uma discordância entre as ordens da história e do relato. Da mesma forma que ocorre em outras narrativas, o conto de Lídia Jorge comporta mais de uma sequência narrativa, visto que cada uma delas apresenta uma articulação de uma história mínima (REIS; LOPES, 2007). O quadro a seguir (Ilustração 1) resume o que se passa em "Testemunha", de acordo com o esquema canônico da narrativa, sendo a segunda linha a recordação de peso maior na história $\left(\mathrm{D}_{3}\right)$, devido à sua extensão no relato e à sua importância no conjunto do conto.

\footnotetext{
${ }^{3}$ Todo o conto é narrado em terceira pessoa, inclusive os pensamentos da protagonista que se davam no momento presente da ação. Esse tipo de focalização, denominado focalização zero, excede o limite de conhecimento de uma personagem da história e ainda do exterior observado. Em "Testemunha", a descrição da cena se dá por meio de como o narrador vê e não como vê uma personagem. Com esse foco narrativo, percebe-se melhor a dinâmica que se dá entre a descrição do mundo exterior com o mundo interior da protagonista; com aquele contribuindo na compreensão deste (GENETTE, s/d; GONÇALVES, 2000; REIS; LOPES, 2007). A descrição de como Zuzete se portava antes de receber a visita e da cena do banheiro, em que esta lanchava sozinha, são exemplos que comprovariam satisfatoriamente a onisciência por parte daquele que narra a história.
} 


\begin{tabular}{|c|c|c|c|}
\hline \multicolumn{4}{|c|}{ (Transformação) } \\
\hline $\begin{array}{l}\text { Zuzete antes da chegada } \\
\text { da visita. }\end{array}$ & $\begin{array}{c}\text { As lembranças, que } \\
\text { acometem Zuzete, } \\
\text { referentes à sua relação } \\
\text { com Sandro e ao tempo } \\
\text { em que vivia no Vale da } \\
\text { Vaca. }\end{array}$ & $\begin{array}{l}\text { Zuzete não exterioriza ao } \\
\text { interlocutor o que } \\
\text { rememora do tempo de } \\
\text { infância. }\end{array}$ & $\begin{array}{l}\text { Zuzete ainda aflita se } \\
\text { despedindo da visita. }\end{array}$ \\
\hline (Estado Inicial) & (Complicação) & (Resolução) & (Estado Final) \\
\hline $\begin{array}{l}\text { Zuzete no trigal no Vale } \\
\text { da Vaca. }\end{array}$ & $\begin{array}{l}\text { Laurentino e outros } \\
\text { meninos violentando } \\
\text { Zuzete. }\end{array}$ & $\begin{array}{c}\text { O pai de Zuzete indo até } \\
\text { a escola resolver o } \\
\text { ocorrido com a } \\
\text { professora. }\end{array}$ & $\begin{array}{l}\text { Zuzete não retornando } \\
\text { mais à escola. Sua } \\
\text { mudança com seu pai } \\
\text { para os Estados Unidos. }\end{array}$ \\
\hline
\end{tabular}

Ilustração 1 - Narrativa Primeira e Analepse (cena do trigal) em “Testemunha”.

A partir da análise do esquema, vê-se que o interlocutor provoca em Zuzete a evocação de uma cena num trigal que marcou sua vida, sendo ele testemunha de todo o sofrimento passado pela protagonista. A presença do interlocutor perturba ainda mais o suposto estado de equilíbrio em que a personagem principal se encontrava, sendo restabelecido parcialmente somente no ato da despedida, visto que antes mesmo da chegada da visita nota-se a aflição de Zuzete. Sendo assim, a sequência do conto se articula a partir de um processo dinâmico envolvendo estado inicial, complicação (ou força perturbadora), transformação, resolução (ou força equilibrante) e estado final (REIS; LOPES, 2007).

Como já mencionado, o retrospecto é feito numa exposição que interrompe a ação principal, que volta ao seu curso, por vezes, sem que aquela tenha terminado. As sequências retrospectivas são intercaladas às sequências do momento narrado, percebe-se uma quebra da continuidade do discurso, que evoca fatos ora sem indicar ao leitor. As analepses ocorrem em função do estilo direto livre, intercalando momentos anteriores ao momento da visita (NUNES, 2008), como se pode notar no trecho:

Zuzete levava mas era, dentro da algibeira do bibe da cor de encardido, um pedaço de pão com banha [...] e apesar de trazer às costas a dúvida do atraso, apanharei não apanharei, esquecia-se ainda por cima do primeiro dever. Porque mesmo à esquerda de quem entrava, por cima do quadro negro, ficava um cristo de braço aberto e perna entalada, cabeça pendida, mostrando os espinhos sem se mexer. Hirto e morto. Jesus, meus meninos (JORGE, 1983, p. 36-37; grifo nosso). 
As evocações presentes, no decorrer do conto, não interferem na narrativa primeira, uma vez que sua função é esclarecer ao leitor os antecedentes da vida de Zuzete (GENETTE, s/d). Sem as analepses não se pode saber onde, quando e o quê aconteceu com a personagem; informações que auxiliam na compreensão do motivo de sua tristeza ao se lembrar de suas tias: Zuzete vai embora do Vale da Vaca com seu pai, deixando-as por lá, em uma circunstância que, certamente, também gerou tristeza em suas tias tanto por terem ficado sozinhas em condições precárias, quanto pelo ocorrido com a sobrinha, que não deve ter sido esquecido por lá.

A única indicação do que seria uma antecipação temporal (prolepse) aparece no final do conto: "Eu direi" (JORGE, 1983, p. 39). Este enunciado é uma fala do interlocutor, uma resposta à Zuzete, confirmando que assim que passar pelo Vale da Vaca dirá às suas tias "que dentro de um ano, de dois, de três, o mais tardar, estarás de volta” (JORGE, 1983, p. 39). Vêse, então, um acontecimento posterior ao presente da ação, devido à frase enunciar um fato que há de se realizar (GENETTE, s/d).

A alteração da ordem do tempo serviu nesta narrativa como recurso para mostrar o psicológico de Zuzete, revelando sua aflição e seu tormento por um fato que se sucedeu há muito tempo. Assim, a posição temporal do conto não se mantém fixa, uma vez que é possível apontar o tempo da enunciação, o tempo do diálogo entre os locutores e o tempo em que Zuzete rememora sua história (GENETTE, s/d). Pontos abordados a seguir.

\section{O aspecto linguístico como recurso para a configuração da analepse}

A partir do jogo entre os vários níveis temporais, procedentes da "reflexividade do próprio ato configurante" (RICOEUR, 1995, p. 110), os traços fictícios do tempo passaram a ser notáveis, desde que houve a mudança de foco do enunciado para a enunciação. Dessa forma, a categoria gramatical do tempo também se aplica ao conteúdo do discurso narrativo (GENETTE, s/d).

Por conta das alterações temporais, que contam fatos passados, "Testemunha" se adjetiva como narração ulterior. Os tempos gramaticais e as marcas temporais utilizados indicam esse tipo de narração. Porém, vale ressaltar que não se pode atribuir ao conto uma única tipologia, pois, além do relato primeiro e das analepses terem pesos parecidos, o diálogo das personagens é marcado no tempo presente, indicando, portanto, uma narração simultânea (GENETTE, s/d).

A preocupação da escritora não é somente com a disposição da sequência de eventos; Lídia Jorge se preocupa também em apresentar o mundo ficcional da personagem principal, 
mostrando como Zuzete vive, age e sente. E é por meio linguístico que a narrativa representa esse mundo, com as práticas das ações dentro de um determinado tempo e espaço.

A ordenação dos fatos se torna retrospectiva nos atos das falas das personagens e do pensamento de Zuzete, tendo como indícios expressões adverbiais de tempo e de lugar citadas em alguns momentos: "agora", “ontem", "lá” (NUNES, 2008). Com isso, as mudanças temporais estão relacionadas com o tempo da enunciação, com o narrador relatando o que se sucede em três tempos verbais, de acordo com cada momento: pretérito perfeito, presente e pretérito imperfeito.

É a partir dos enunciados das personagens e a respeito delas (enunciação do narrador), que é demarcado o tempo (NUNES, 2008). Em "Zuzete de frente, Zuzete de lado, e de súbito Zuzete abriu os braços, com uma lufada de rubor no rosto, um enorme amplexo de encontro [...]" (JORGE, 1983, p. 35; grifo nosso), o verbo destacado é determinante para se saber que o tempo da enunciação está sendo contado no passado, que o narrador está contando um fato concluído. Sendo assim, o pretérito perfeito é o tempo do acontecimento relatado na narrativa primeira, caracterizado aqui como passado primeiro $\left(\mathrm{P}_{1}\right)$.

O emprego do presente histórico (presente narrativo) também é notado no conto para marcar as falas das personagens, tanto da principal, quanto das secundárias, em situações que relatam fatos passados. Ou seja, há a utilização do tempo presente com significação de pretérito perfeito (REIS; LOPES, 2007): “Sou eu, Zuzete. És tu, que surpresa, não tenho palavras. Sabes que sou casada" (JORGE, 1983, p. 35; grifo nosso); "Eram duas molduras repletas de gravidade e esquadria, Zuzete, tu lembras-te como eu" (JORGE, 1983, p. 37; grifo nosso); "minha senhora, estou aqui para tirar isto a limpo" (JORGE, 1983, p. 38-39; grifo nosso).

Dessa maneira, excluir o presente significa excluir as relações entre as personagens. O interlocutor, por exemplo, quando se refere à Zuzete, utiliza a segunda pessoa do singular: "Mas tinham ambos, tu transportá-los, Zuzete" (JORGE, 1983, p. 37; grifo nosso); "Ora conta lá como conheceste o Sandro" (JORGE, 1983, p. 38; grifo nosso). Isso porque o tempo presente "marca a contemporaneidade entre a coisa enunciada e a instância do discurso" (RICOEUR, 1995, p. 112).

Os dêiticos existentes no conto "Testemunha" também funcionam dentro de um intercâmbio linguístico que ocorre entre os locutores e obviamente pelo narrador, "e sem o qual o enquadramento cronológico seria um molde abstrato" (NUNES, 2008, p. 22). No decorrer do conto, pode-se enumerar diversas referências temporais: "grandes luas no mês de 
janeiro", "quatro estações do ano", "aos domingos", "chega o fim de setembro", "a cor da decência que o castanho dá aos documentos de infância", "neste momento", "numa tarde", "no dia seguinte", "nove horas em ponto", "de tarde", "demora", "dentro de um ano, de dois, de três, o mais tardar", entre outros. Percebe-se que há tanto indícios temporais diretos, quanto indiretos.

Em relação a esse último, mesmo com a menção de que as recordações de Zuzete consideradas aqui como passado segundo $\left(\mathrm{P}_{2}\right)$ - se referem a um período no "Vale da Vaca, a tantos do tantos de mil novecentos e cinquenta e tantos" (JORGE, 1983, p. 37), é possível delimitar os meses referentes à época escolar e, consequentemente, a cena maldosa entre as crianças no trigal. Ao descrever as searas deste lugar, que "ainda não tinham o loiro fulvo da palha" (JORGE, 1983, p. 38), o narrador menciona que seria em abril ou maio: "Éramos tão pequenos, e foi num abril ou num maio, talvez abril, porque os trigais ainda não estavam maduros, mas eram compridamente altos e tinham as espigas erectas como gargantas" (JORGE, 1983, p. 36). Outra referência feita em relação a este tempo é a expressão "naquele tempo ainda o almoço se chamava jantar" (JORGE, 1983, p. 36).

O período escolar é identificado, primeiramente, pela expressão "entrava depois de já se ir a meio abcedário da caligrafia [...] esquecia-se ainda por cima do primeiro dever" (JORGE, 1983, p. 36; grifo nosso). Foi depois da aula, quando retornava para casa, que Laurentino, "já de dentes mudados, tão grande que lhe assomava um buço" (JORGE, 1983, p. 38), para dizer que era mais velho do que as outras crianças, agrediu Zuzete. Estas marcas temporais são importantes para a composição da narrativa, por serem inferências indiretas que mostram que os envolvidos no estupro se tratam de crianças ainda e compreender os traumas, que perduraram durante muito tempo.

Em "é necessário atravessar meio século de vidas na asa de um avião americano" (JORGE, 1983, p. 39), pode-se depreender o tempo entre a saída de Zuzete do Vale da Vaca e de sua chegada aos Estados Unidos: uma distância de cinquenta anos. Essa analepse, a recordação da cena no trigal $\left(\mathrm{D}_{3}\right)$, de maior importância em relação às outras na história, percorreu meio século, ou seja, o sofrimento da personagem se estendeu durante todo esse tempo. Com isso, o leitor percebe a dimensão e a gravidade que tal fato proporcionou à vida de Zuzete.

Além dos pontos mencionados, como se sabe e pode ser notado, o tempo linguístico se junta às coordenadas espaço-temporais, que são fornecidas pelo tempo cronológico (NUNES, 2008). Sendo assim, cada enunciado na narrativa institui relações com o espaço, 
tendo como foco estruturante o seu locutor. A história é contada por um narrador, que transcreve a conversa de Zuzete com o interlocutor e, por vezes, falas de outros locutores que aparecem em determinados momentos, como a da professora, quando é descrita a sala de aula $\left(D_{1}\right)$; a do pai de Zuzete, quando vai à escola falar com a professora sobre o que aconteceu com sua filha $\left(\mathrm{D}_{3}\right)$, e a de Sandro, quando chega em casa. Isto é, a partir dessas personagens, o leitor passa a ter noção do lugar e do tempo (REIS; LOPES, 2007).

Bem, por lá tudo na mesma, um sol brilhante, umas grandes luas no mês de janeiro, ralos cantando pelas noites fora, quando chove há charcos, vem o vento e seca-os, passam nuvens, vêm aves, as quatro estações do ano. Também andam a construir casas de vários andares à porta da estrada (JORGE, 1983, p. 35; grifo nosso).

Por meio deste trecho pode-se saber o espaço que as personagens ocupam no relato primeiro e o local que se remete às lembranças da protagonista. Trata-se de uma fala da visita, descrevendo como está o lugar onde passaram a infância. O dêitico "lá" é uma antecipação desse determinado local que, posteriormente, vê-se que se trata do Vale da Vaca, como se observa também em outro momento, em um enunciado do interlocutor: "Deixa lá, Zuzete, assim que por lá passar lhes digo que dentro de um ano, de dois, de três, o mais tardar, estarás de volta" (JORGE, 1983, p. 39; grifo nosso).

Já no trecho a seguir, é a expressão "avião americano" que indica o possível lugar em que a protagonista se encontra, no caso, nos Estados Unidos. Essa possibilidade explica a frase "ponte de gente feita de propósito para ligar continentes a continentes em redor da terra" (JORGE, 1983, p. 39). Isso porque, com a saída da protagonista do Vale da Vaca (emigração), todos de braços dados simbolizam o elo entre os continentes americano, representado pelos filhos, e europeu, representados por Zuzete e Sandro. Os nomes dos dois filhos de Zuzete, Donald e Margaret, também sustentam ulteriormente a hipótese da ida da protagonista aos Estados Unidos, uma vez que os nomes não são de origem portuguesa.

\footnotetext{
Sandro, esse ragazzo, compreende e ri pela primeira vez. Assim de lado, lembra o perfil de Laurentino de mão estendida a desafiar os estoiros. Vê-se que tem atrás de si um velhíssimo pai a pastar o gado pelas ervas da Calábria, e que também para lá se voltar é necessário atravessar meio século de vidas na asa de um avião americano (JORGE, 1983, p. 39; grifo nosso).
}

As antecipações percebidas no relato primeiro só podem ser entendidas, em sua maioria, graças às sucessivas anacronias recorrentes durante a narrativa. A partir do mencionado até o momento, pode-se visualizar a estrutura do conto (espaço, tempo verbal) da seguinte maneira: 


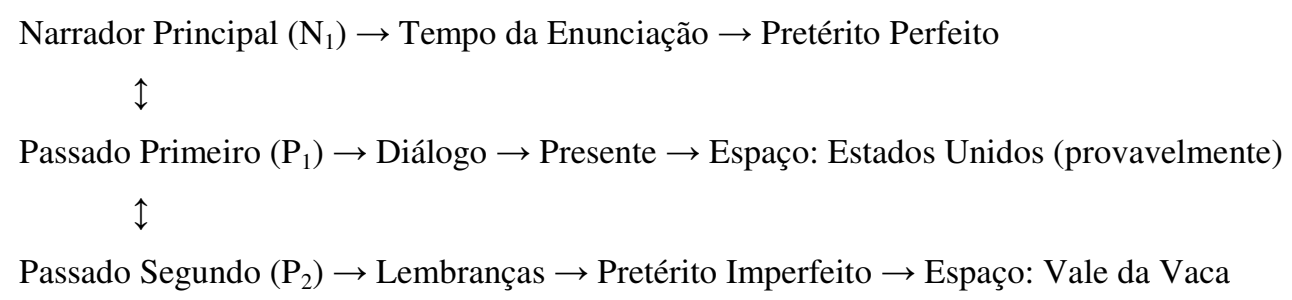

Ilustração 2 - Esquema referente à estrutura espaço-temporal de "Testemunha".

O narrador, portanto, está relacionado a todas as enunciações apresentadas durante o relato, sendo as marcas de diferenciação os tempos verbais. O posicionamento temporal do narrador, como já dito, releva uma narração ulterior; o narrador relata a história como concluída e totalmente conhecida. Por ter um conhecimento ilimitado, ele faculta as informações que considera pertinentes para o conhecimento da história: resumindo ou estendendo o tempo da narrativa (supressão dos lapsos cronológicos, realização de retrospecções, entre outros) (REIS; LOPES, 2007).

Essa estrutura, visualizada na Ilustração 2, mostra a alternância espaço-tempo de tal narrativa que indica também a oscilação da protagonista entre os espaços com cada qual referente ao seu tempo: o tempo presente configurado no espaço americano e o tempo passado no espaço português. Zuzete, simultaneamente, encontra-se nos dois, seu presente é tomado pelo passado, pois mesmo estando no continente americano suas lembranças, que são constantes, estão ligadas ao período em que vivia no Vale da Vaca (Portugal).

Segundo Ricoeur (1995), os tempos verbais cooperam para a narrativização, não só pelo jogo de suas diferenças, mas pela sua "disposição sucessiva no encadeamento da narrativa" (p. 111; grifo do autor). O manejo dos tempos verbais, como visto neste conto, produz um efeito de originalidade e de contemporaneidade; isso por observar, na sequência narrativa, verbos nos pretéritos perfeito e imperfeito como recurso de mudança espacial.

A repetição é outro recurso estilístico utilizado pela escritora. A repetição da conjunção "mas" explicita o mencionado acima. Essa, na maioria das vezes, mostra a retomada de uma situação que está sendo contada e que foi interrompida. A ocorrência se dá dez vezes e, em alguns momentos, o "mas" serve como uma contraposição ora com o que está sendo descrito no relato primeiro, passando para as recordações da personagem, ora como uma retomada da retrospecção para a cena do encontro: "Mas naquele tempo ainda o almoço se chamava jantar, e Zuzete era a única que não levava cesto" (JORGE, 1983, p. 36), a personagem mostrava a cozinha à visita quando foi acometida pela lembrança; "Mas agora 
Zuzete ia e vinha, via-se que punha uma mesa festiva arrancando panos dobrados do fundo das gavetas" (JORGE, 1983, p. 38), ao ser descrita a cena da retrete a conjunção evidencia a volta ao momento presente da história.

No aspecto geral da narrativa, pelo meio linguístico, percebe-se a situação atual de Zuzete, que contraria certa frase dita pelo interlocutor: "E a gente a mudar, a mudar um pouco com o tempo" (JORGE, 1983, p. 35). Anteriormente, ele estava a narrar como se encontrava o Vale da Vaca, sua beleza e suas condições naturais (estações do ano) que permaneciam sem modificações e o espaço físico a sofrer alterações com a construção de prédios. Passaram-se anos e a personagem continua se sentindo atormentada por toda a humilhação sofrida quando criança naquele local. Nota-se que há uma necessidade de mudança que não ocorre. $\mathrm{O}$ passado ainda é constante na vida de Zuzete.

Isso mostra que, apesar da ruptura temporal e espacial na narrativa, a saída física da protagonista do Vale da Vaca, como maneira de solucionar os problemas que a aflige, foi uma tentativa ilusória. Ela não deixa de sofrer, além de ser dominada por uma ideia fixa e um comportamento desordenado representados pela fragmentação das cenas (GONÇALVES, 2000).

Todos os aspectos temporais explicitados nesta parte do artigo serviram para mostrar a importância dos recursos linguísticos como contribuição para se entender e indicar as mudanças da ordem temporal da narrativa. Mesmo sendo evidente que o tempo também é indicado por meio do conteúdo narrativo e das relações de encaixe temporal, da justaposição das cenas: o presente e o passado se encontrando por meio do mundo interior de Zuzete (NUNES, 2008).

\section{Conclusão}

Ao contrário do discurso da narrativa clássica, em relação à disposição dos fatos, “Testemunha" apresenta a inversão da ordem temporal dos acontecimentos narrados, por vezes, sem informar ao leitor - fornecendo alguma referência - de que isso ocorrerá. O fato de este conto ser contemporâneo permite uma dinâmica entre as categorias narrativas, no que diz respeito à apresentação do diálogo, à mudança de perspectiva e às variações temporais.

Apesar de haver algumas dessas características, assim como outras, Lídia Jorge se apropriou do tempo como categoria central neste conto. Isso porque as lembranças dominam a maior parte da narrativa, sendo evidenciadas relações temporais, que consistem em retrospecções e em retornos feitos à posição inicial, intercalando o momento da visita (agora) com as recordações da personagem (antes) (GENETTE, s/d; REIS; LOPES, 2007). 
As recordações da protagonista são episódios evidentemente anteriores ao ponto de partida temporal, que englobam a noção da narrativa retrospectiva da personagem (GENETTE, s/d), principalmente, aos tempos de escola. Sendo assim, os recuos temporais recordados pela protagonista e contados pelo narrador fazem com que a própria estrutura narrativa mostre o tormento vivido pela personagem: a instabilidade de Zuzete é mostrada pela alteração da ordem do tempo.

As informações contidas possibilitam ao leitor encontrar a cronologia e, ainda, se a ordem segue ou não uma sequência. Os aspectos de ordenação mostram como pode ser percebido o encadeamento da narrativa, a partir do estudo da articulação do tempo e não de acordo com a lógica (BAL, 2009; GENETTE, s/d). Como se pode observar, a relação do tempo com os acontecimentos relatados no conto está tanto nas experiências vividas pela personagem principal, quanto na enunciação linguística da narrativa (NUNES, 2008).

As analepses, portanto, têm um papel fundamental na configuração formal e na orientação de sentido em "Testemunha". Pelo fato de os recuos temporais constituírem "um processo de ilustração do passado" (REIS; LOPES, 2007, p. 31) da personagem principal; recuperando acontecimentos anteriores, que servem como conhecimento necessário para conceder à história uma coerência interna.

Este procedimento adotado por Lídia Jorge, em sua totalidade, visa também um efeito teatral. A maneira de o narrador exprimir a história é, desde o início, gestual, remetendo-se ao movimento da personagem e sua mudança de humor. Além disso, as alterações temporais e a mudança de foco servem como indícios desse efeito. Pode-se dizer que a cena de estupro da protagonista se assemelha ao ato teatral, uma vez que, trata-se de uma ação completa - contendo início, meio, fim e todos os elementos da narrativa - separada por um intervalo de tempo.

Enfim, todas as mudanças do tempo e do espaço (Ilustração 2) presentes neste conto criaram um jogo narrativo feito em torno, no caso, da temporalidade, que dá à história uma dinâmica, por assim dizer, complexa. Isso porque a estrutura estética de "Testemunha" está intimamente ligada ao que seria o mundo interior de Zuzete, isto é, o (re)arranjo das ordens da história e do relato (mudanças entre o tempo da enunciação, o tempo do diálogo e o tempo das evocações de fatos passados) simboliza o estado de espírito caracterizado pela desordem e pelo tormento da protagonista. 
Agradecimentos: Agradeço aos professores Dr. Rogério Santana, por me apresentar os escritos de Lídia Jorge, e Dr. Heleno Godoy, por compartilhar todo o seu conhecimento sobre Narratologias.

\section{Referências}

BAL, Mieke. Teoría de la narrativa: una introducción a la narratología. 8. ed. Traducción de Javier Franco. Madrid: Ediciones Cátedra, 2009. 164 p.

GENETTE, Gérard. Discurso da narrativa. Tradução de Maria Alzira Seixo. Lisboa: Vega Universidade, s/d. 279 p.

GONÇALVES, Maria Madalena. Lídia Jorge: a arte de narrar "Maridos e outros contos", 2000. Disponível em: < http://geocities.ws/ail_br/lidiajorgeaartedenarrar.html >. Acesso em: 31 out. 2011.

JORGE, Lídia. Testemunha. Revista Colóquio / Letras, Lisboa, n. 73, p. 35-39, mai. 1983. Disponível em: < http://coloquio.gulbenkian.pt/index.html >. Acesso em: 04 out. 2011.

NUNES, Benedito. O tempo na narrativa. 2. ed. São Paulo: Editora Ática, 2008. 84 p.

REIS, Carlos; LOPES, Ana Cristina M. Dicionário de narratologia. 7. ed. Coimbra: Almedina, 2007. 459 p.

RICOEUR, Paul. Tempo e narrativa. Tradução de Marina Appenzeller. São Paulo: Papirus Editora, 1995. v. 2.

RUDIN, Ernst. Introducción a la terminología de Genette. Zurich, 2003. Disponível em: http://www.elneto.com/hispa/ZH2003/index.html >. Acesso em: 19 mar. 2007.

TODOROV, Tzvetan. As categorias da narrativa literária. In: BARTHES, Roland et al. Análise estrutural da narrativa: Pesquisas Semiológicas. 2. ed. Tradução Maria Zélia Barbosa Pinto. Rio de Janeiro: Vozes Limitada, 1972. p. 209-254.

[Recebido em junho de 2013 e aceito para publicação em outubro de 2013]

\section{The time on the short story "Witness" by Lidia Jorge}

Abstract: The aim of this paper is to analyze the time line structure in the short story "Witness" by Lidia Jorge, through the theoretical application of the narrative text study methodology, which is proposed by Gérard Genette, and also using other theorists who have studied this subject: Paul Ricoeur and Benedito Nunes. This tale allows this kind of approach because the writer uses the narrative time as a central category in her story, evoking childhood and school scenes, recollected by the main character. The change in the temporal order (anachrony) is evident in this narrative, and the discursive organization is subverted through temporal setbacks (analepses), which contribute to the motivation of the story. As a method, the time line survey contributes to the understanding of the configuration of analepses in the narrative discourse of "Witness", as well as in its classification regarding the narrative 
typology: subsequent narrative, as a whole. Because it is a contemporary tale, inversions are noted in the order of the events, sometimes without saying, being reasonable, therefore, the analysis of the linguistic aspect (expressions, time evidence) in order to assist in the identification of time variations and, consequently, in the retrospective, movement of Lidia Jorge's tale.

Keywords: Narrative time. Anachrony. Analepses. Lidia Jorge. "Witness".

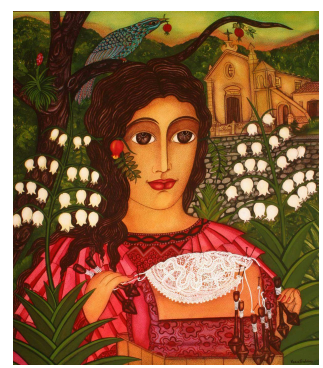

